\title{
3D modelling of the flow of self-compacting concrete with or without steel fibres. Part I: slump flow test
}

\author{
R. Deeb · S. Kulasegaram • B. L. Karihaloo
}

Received: 12 December 2013 / Revised: 10 February 2014 / Accepted: 19 February 2014 / Published online: 4 April 2014

(C) Springer International Publishing Switzerland 2014

\begin{abstract}
In part I of this two-part paper, a three-dimensional Lagrangian smooth particle hydrodynamics method has been used to model the flow of self-compacting concrete (SCC) with or without short steel fibres in the slump cone test. The constitutive behaviour of this non-Newtonian viscous fluid is described by a Bingham-type model. The 3D simulation of SCC without fibres is focused on the distribution of large aggregates (larger than or equal to $8 \mathrm{~mm}$ ) during the flow. The simulation of self-compacting high- and ultra-highperformance concrete containing short steel fibres is focused on the distribution of fibres and their orientation during the flow. The simulation results show that the fibres and/or heavier aggregates do not precipitate but remain homogeneously distributed in the mix throughout the flow.
\end{abstract}

Keywords 3D simulation - Self-compacting concrete . Non-Newtonian viscous flow $\cdot$ Smooth particle hydrodynamic $(\mathrm{SPH}) \cdot$ Short steel fibres

\section{Introduction}

Computer modelling or simulation is nowadays an indispensable tool for solving complex engineering problems. It can replace expensive experimental tests in order to save time, effort and materials. Due to the need for highly durable structures, self-compacting concrete (SCC) with its distinctive flow-ability, passing ability and segregation resistance has been developed, and is increasingly replacing conventional

R. Deeb · S. Kulasegaram $(\varangle) \cdot$ B. L. Karihaloo

School of Engineering, Cardiff University, Cardiff CF24 3AA, UK

e-mail: kulasegarams@cardiff.ac.uk

B. L. Karihaloo

e-mail: karihaloob@cardiff.ac.uk vibrated concrete in the construction industry. The mixture of SCC is strongly dependent on the composition and characteristics of its constituents both in its fresh and hardened states. The prediction of its filling behaviour is very difficult especially in the presence of reinforcing steel and in formworks of complex shapes. However, an understanding of the behaviour and the flow characteristics is crucial to achieving a high quality SCC. The most cost-effective way to gain such an understanding is by performing numerical simulations, which will enable us to fully understand the flow behaviour of SCC with and without steel fibres and to reveal the distribution of larger aggregate particles and of fibres and their orientations inside the formworks.

As an SCC mix consists of particles of different sizes and shapes, it is simpler and more appropriate to use meshless particle based numerical techniques to simulate the flow. A range of SCC mixes with 28-day cube compressive strength between 35 and $160 \mathrm{MPa}$ has been modelled using a Lagrangian smooth particle hydrodynamics (SPH) method. Other computational strategies that have been tried for particle suspensions include the immersed boundary method [1], and the fictitious domain method [2].

SCC mixes of varying strengths and performance were developed to meet the flow-ability, passing ability and segregation resistance criteria using the slump cone flow, J-ring and L-box tests [3]. In normal strength SCC (compressive strength in the range 30-80 MPa) which do not usually contain any steel fibres, it is the distribution of large coarse aggregate particles (size 8 and $10 \mathrm{~mm}$ ) that needs to be monitored during the flow in order to ensure there is no segregation of these particles from the paste. The simulation of these SCC mixes will therefore emphasise the distribution of large aggregate particles of different sizes throughout the flow in the $3 \mathrm{D}$ configurations. On the other hand, the simulation of high strength SCC mixes (compressive strengths in the range 

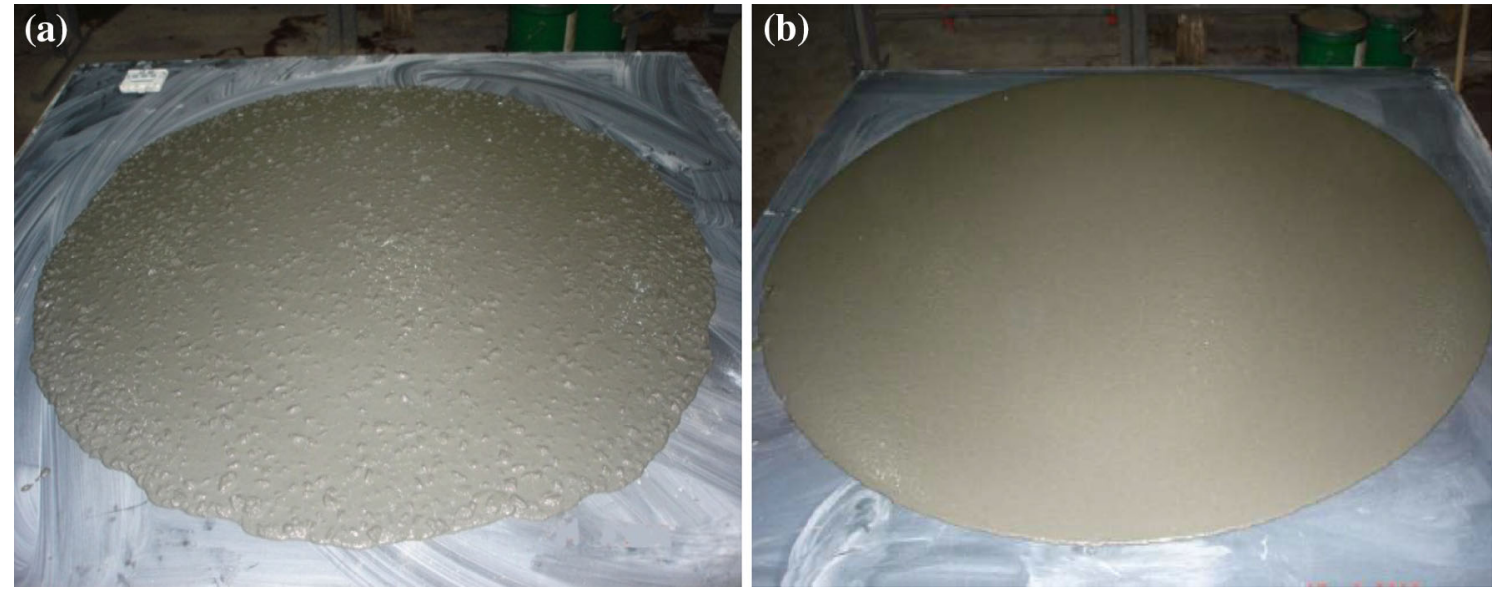

Fig. 1 Horizontal spread of SCC Mix 1 (a) and Mix 3 (b) without fibres

100-160 MPa) which contain between 0.5 and $2.5 \%$ by volume steel fibres will focus on the distribution of fibres and their orientations during the flow in $3 \mathrm{D}$ configuration. A twodimensional or axisymmetric simulation of such mixes [4] is rather misleading because all the fibres appear in a single plane. The accurate picture can only be gained by using the three-dimensional flow simulation which shows the actual distribution of fibres and their orientations during the flow.

In the work presented here, a novel but simple methodology has been developed to simulate the flow of SCC containing (a) coarse aggregate particles of various sizes, and (b) steel fibres. A comparison between the experimental and simulation results is encouraging, thus improving our understanding of the flow and filling behaviour of SCC and providing an insight into the distribution of fibres and their orientations during the flow.

\section{Development of mixes}

An extensive laboratory study was conducted in Cardiff University to produce different grades of normal and high strength SCC mixes with and without fibres (with nominal 28-day cube compressive strengths of 35, 45, 60, 80, 100, 140 and $160 \mathrm{MPa}$ ) using a particular type of steel fibre, $30 \mathrm{~mm}$ long Z560 Dramix fibres with crimped ends, for mixes with steel fibres [3,5]. Four of these will be presented in this paper.

A SCC mix has on the one hand, to be as fluid as possible to ensure that it fills the formwork under its own weight, but on the other, it has to be a stable mixture to prevent the segregation of solids during the flow [6]. In other words, it has to flow as a homogeneous viscous fluid. Therefore, SCC mixes are designed to satisfy flow-ability and cohesiveness (i.e. resistance to segregation) criteria using the slump cone test. In this test, the time for the SCC mix to spread to a diameter of $500 \mathrm{~mm}\left(\mathrm{t}_{500}\right)$ after the cone filled with the mix has been suddenly lifted is recorded, as well as the diameter of the spread when the flow stops. The resistance to segregation is checked visually.

The passing ability of a SCC mix is tested using the J-ring and the L-box apparatus [7]. A SCC mix meets the passing ability test when it flows through the spaces between the rods without any of the large aggregate particles or fibres being blocked.

The addition of steel fibres improves the mechanical properties and the ductility of SCC in much the same manner as in vibrated concrete. However, the fibres greatly impair the workability of SCC because of their elongated shape and large surface area. The amount of fibre added to a SCC mix is therefore limited and depends on the fibre type used and the composition of the SCC mix. The maximum amount of fibre needs to be determined in such a way as to cause the least decrease in the workability, whilst maintaining good flow and passing ability. In order to make the best use of the fibres, they need to be homogeneously distributed in the mix without clustering [8].

The mixes so produced are shown in Figs. 1 and 2 and designated 1-4 in Table 1 . They all satisfied the flow-ability and passing ability criteria and showed no visible signs of segregation.

The plastic viscosity of each mix was calculated using the micromechanical procedure described in [9] and the plastic viscosity of the homogeneous paste. This procedure is based on the rheology of concentrated suspensions [10-14] and it is known to predict accurately in a stepwise manner the plastic viscosity of heterogeneous SCC mixtures beginning with the plastic viscosity of the homogeneous cement paste. The measurement of the plastic viscosity of heterogeneous SCC, especially those containing steel fibres using the rheometers often gives inaccurate results with a large scatter. In the micromechanical procedure [9], concrete is treated as a twophase suspension in which the solid phase is suspended in a 

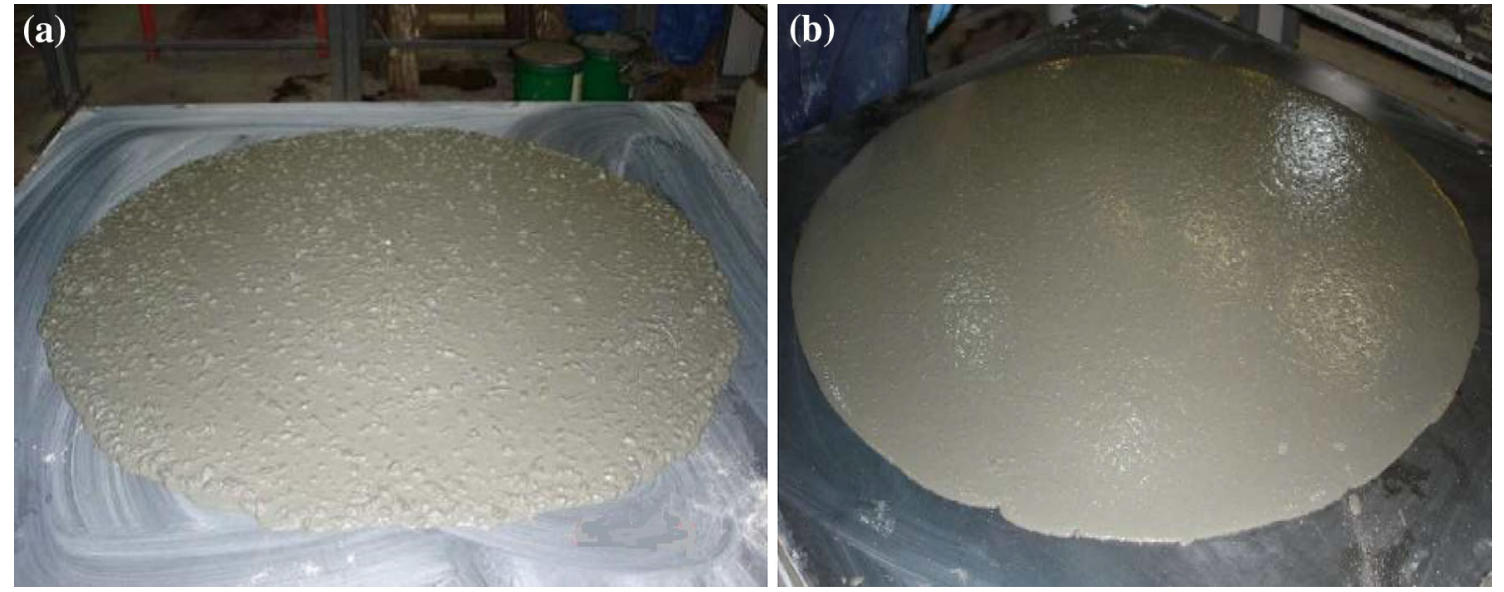

Fig. 2 Horizontal spread of SCC Mix 2 (a) and Mix 4 (b) with fibres

Table 1 The mix constituents of Mixes 1-4

\begin{tabular}{|c|c|c|c|c|}
\hline Constituents & Mix 1 & Mix 2 & Mix 3 & Mix 4 \\
\hline Cement (kg) & 500 & 500 & 543.5 & 543.5 \\
\hline Micro-silica (kg) & 75 & 75 & 214 & 214 \\
\hline Ground granulated blast furnace slag (GGBS) (kg) & - & - & 311.5 & 311.5 \\
\hline Limestone powder $<2 \mathrm{~mm}$ & 200 & 200 & - & - \\
\hline Coarse aggregates $(\mathrm{kg})$ (crushed limestone) $<10 \mathrm{~mm}$ & 833 & 833 & - & - \\
\hline Sand $<2 \mathrm{~mm}$ & 700 & 700 & - & - \\
\hline \multicolumn{5}{|l|}{ Quartz sand (kg) } \\
\hline 9-300 $\mu \mathrm{m}$ & - & - & 470 & 470 \\
\hline $250-600 \mu \mathrm{m}$ & - & - & 470 & 470 \\
\hline Water (kg) & 138 & 138 & 188 & 188 \\
\hline Fibres (30 mm long with crimped ends, volume fraction) & - & $0.5 \%$ & - & $2.5 \%$ \\
\hline Super-plasticiser/water & 0.14 & 0.14 & 0.28 & 0.28 \\
\hline Water/(cement+micro-silica+GGBS) & 0.24 & 0.24 & 0.18 & 0.18 \\
\hline Density $\left(\mathrm{kg} / \mathrm{m}^{3}\right)$ & 2454.0 & 2480.7 & 2242.4 & 2381.4 \\
\hline Flow spread (mm) & 805 & 760 & 910 & 850 \\
\hline $\mathrm{t}_{500}(\mathrm{~s})$ & 2.20 & 3 & 3 & 3 \\
\hline Plastic viscosity (Pa s) & 9.77 & 42.1 & 3.1 & 54.3 \\
\hline Compressive strength (MPa) & 80 & 100 & 140 & 160 \\
\hline
\end{tabular}

viscous liquid phase. The plastic viscosity of the initial liquid phase $\eta_{\mathrm{c} 0}$ (cement, water and super-plasticiser) can be measured accurately using a rheometers [15-18]. The increase in the plastic viscosity of the paste induced by the addition of the solid phase particles is then predicted in stages from a two-phase suspension model. In the first stage, the solid phase is the finest solid material, e.g. micro-silica in the viscous fluid phase (i.e. the paste). In the second stage, the next finest solid is suspended in the viscous fluid phase formed by the two-phase suspension from the first stage. This procedure is continued until all the solid phase constituents have been added. The viscosity of the two-phase suspension is given by the product of the viscosity of the liquid phase and a func- tion that depends on the volume fraction of solid phase and the shape of the particles. The addition of fibres increases the plastic viscosity further. By treating the fibres as rigid slender bodies that only undergo rigid body translation and rotation in the viscous SCC fluid and estimating the resistance offered by the viscous concrete to these motions, the effect of a dilute concentration of steel fibres (volume fraction less than $3 \%$ ) on the plastic viscosity is calculated. In this manner, the plastic viscosity of the fibre-reinforced SCC, designated $\eta$ is given by

$$
\eta=\eta_{N F}\left\{\left(1-\phi_{f}\right)+\frac{\pi \phi_{f} l_{d}^{2}}{3 \ln \left(2 l_{d}\right)}\right\}
$$


Fig. 3 Slump cone test boundary conditions $(P$ pressure, $v_{\mathrm{n}}$ normal velocity, $\boldsymbol{v}_{\mathrm{t}}$ tangential velocity, and $c_{f}$ the dynamic coefficient of friction). Pressure vanishes on a free surface. Note that the condition that the normal pressure gradient vanishes on rigid surfaces is only needed in the solution of the pressure Poisson Eq. (10)
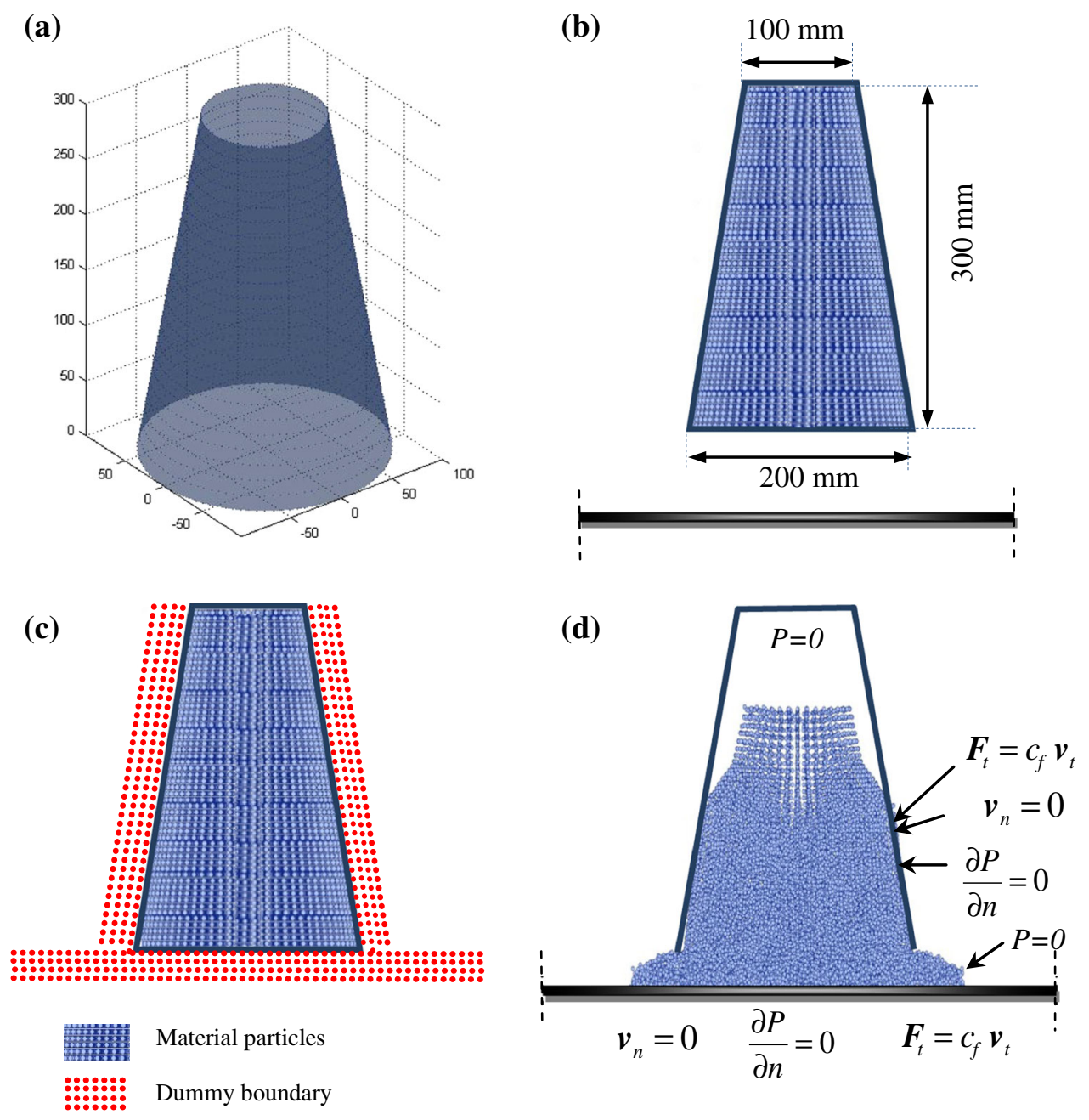

where $\eta_{N F}$ is the plastic viscosity of the viscous concrete mix without fibres calculated in stepwise manner from a twophase suspension model as explain above [9], $\phi_{f}$ is the fibre volume fraction, and $l_{d}$ is the length to diameter ratio of the fibre.

\section{Simulation of flow: governing equations}

In view of its shear rate-dependent response, SCC can be regarded as a non-Newtonian incompressible fluid. Its rheology is best described by a Bingham type model which contains two material properties, the yield stress $\tau_{0}$ and the plastic viscosity $\eta$. It is known however that the yield stress of SCC mixes is very low (around $200 \mathrm{~Pa}$ ) in comparison with normal vibrated concretes (thousands of Pascal) and remains nearly constant over a wide range of plastic viscosities [9]. From a practical computational point of view, it is expedient to approximate the bi-linear Bingham constitutive model with a kink at $\dot{\gamma}=0$ by a scalar continuous function [19]

$$
\tau=\eta \dot{\gamma}+\tau_{0}\left(1-e^{-m \dot{\gamma}}\right)
$$

in which $\mathrm{m}$ is a very large number $\mathrm{m}=10^{5}$. This smooth function is practically indistinguishable from the original bilinear relation. Equation (2) is applicable to each of the three independent shear components of the stress tensor.

The Bingham type constitutive model of the mixes is coupled with the Lagrangian continuity and momentum equations to model the flow of SCC mixes. The isothermal, Lagrangian form of mass and momentum conservation equations are:

$$
\begin{aligned}
& \frac{1}{\rho} \frac{D \rho}{D t}+\nabla \cdot \boldsymbol{v}=0 \\
& \frac{D \boldsymbol{v}}{D t}=-\frac{1}{\rho} \nabla P+\boldsymbol{g}+\frac{1}{\rho} \nabla \cdot \boldsymbol{\tau}
\end{aligned}
$$

where $\rho, \mathbf{t}, \boldsymbol{v}, \mathrm{P}, \mathbf{g}$ and $\boldsymbol{\tau}$ represent the fluid particle density, time, particle velocity, pressure, gravitational acceleration, and shear stress tensor, respectively. Below we shall consider flows in which the density is constant, so that the first term in Eq. (3) vanishes. 
Table 2 Volume fractions of aggregates larger than or equal to $8 \mathrm{~mm}$ in Mix 1 and the particles representing them in the 3D simulation of slump cone test

\begin{tabular}{llllll}
\hline Mix 1 & Particle diameter $(\mathrm{mm})$ & Density $\left(\mathrm{kg} / \mathrm{m}^{3}\right)$ & Volume fraction $(\%)$ & Number of particles & Assigned volume/ particle $\left(\mathrm{mm}^{3}\right)$ \\
\hline Particles $<8 \mathrm{~mm}$ & $<8 \mathrm{~mm}$ & $2,332.4$ & 74 & 19,750 & 195.79 \\
Aggregates $\geq 8 \mathrm{~mm}$ & 10 & 2,800 & 15 & 1,575 & 597.42 \\
& 8 & 2,800 & 11 & 2,256 & 305.88 \\
Total & - & 2,454 & 100 & 23,581 & - \\
\hline
\end{tabular}

Fig. 4 Schematic sketch of particle representation when simulating large aggregate distribution

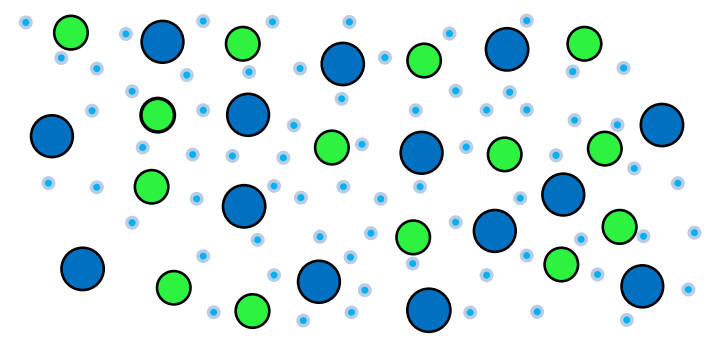

Particles representing large aggregates

Fig. 5 Fibre orientations at time steps $t_{n}$ and $t_{n+1}$
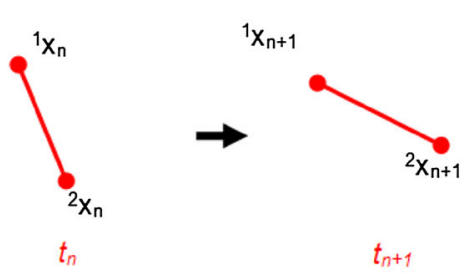

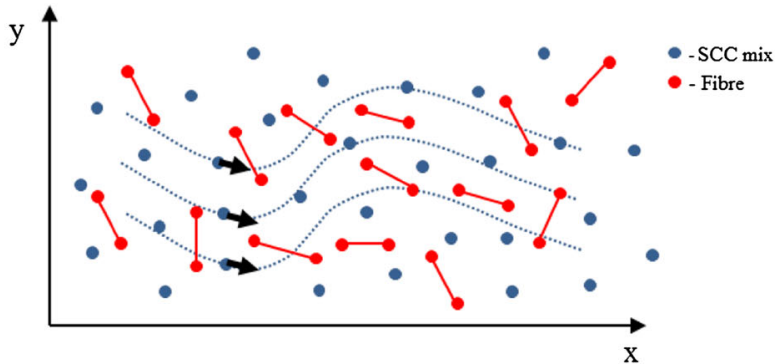

For a non-Newtonian fluid, the shear stress is generally written as:

$\boldsymbol{\tau}=2 \mu(\dot{\gamma}) \boldsymbol{d} \equiv\left(\eta+\frac{\tau_{0}}{\dot{\gamma}}\left(1-e^{-m \dot{\gamma}}\right)\right) \boldsymbol{d}, \quad(\dot{\gamma}>0)$

where $\boldsymbol{d}$ is the rate of deformation and $\mu$ is the effective plastic viscosity which is a function of shear rate. In Eq. (5), $\dot{\gamma}$ is the shear rate which is defined in general by the second invariant of the rate of deformation $\boldsymbol{d}, \dot{\gamma}=\sqrt{\frac{1}{2}\left(t r d^{2}\right)}$.

\section{Numerical modelling}

A projection method based on the predictor-corrector time stepping scheme has been adopted to track the Lagrangian non-Newtonian flow [20-22]. The prediction step is an explicit integration in time without enforcing incompressibility. Only the viscous stress and gravity terms are considered in the momentum Eq. (4) and an intermediate particle velocity $v_{n+1}^{*}$ is obtained as:

$\boldsymbol{v}_{n+1}^{*}=\boldsymbol{v}_{n}+\left(g+\frac{1}{\rho} \nabla \cdot \tau\right) \Delta t$
Then the correction step is performed by considering the pressure term in Eq. (4):

$\frac{\boldsymbol{v}_{n+1}-\boldsymbol{v}_{n+1}^{*}}{\Delta t}=-\left(\frac{1}{\rho} \nabla P_{n+1}\right)$

where $v_{n+1}$ is the corrected particle velocity at the time step $\mathrm{n}+1$.

The intermediate velocity $v_{n+1}^{*}$ is usually not divergencefree but this condition is imposed on the corrected velocity $v_{n+1}$ by enforcing the incompressibility condition from Eq. (3):

$\nabla \cdot \boldsymbol{v}_{n+1}=0$

Hence the intermediate velocity can be projected on the divergence-free space by writing the divergence of Eq. (7), using (8), as

$\nabla \cdot\left(\frac{1}{\rho} \nabla P_{n+1}\right)=\frac{\nabla \cdot \boldsymbol{v}_{n+1}^{*}}{\Delta t}$

Since the density of particles remains constant in the present simulations, Eq. (9) can be rewritten as:

$\nabla^{2} P_{n+1}=\frac{\rho}{\Delta t} \nabla \cdot \boldsymbol{v}_{n+1}^{*}$

where $\nabla^{2}$ is the Laplacian. 
(a) $0.15 \mathrm{~m} / \mathrm{s}$

$0.2 \mathrm{~s}$

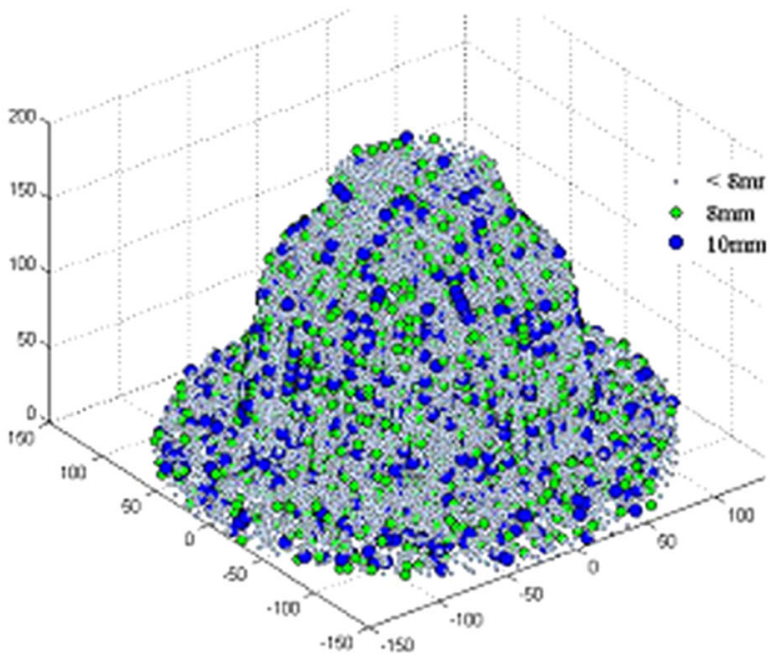

(a)

\section{$0.15 \mathrm{~m} / \mathrm{s}$}

$0.2 \mathrm{~s}$

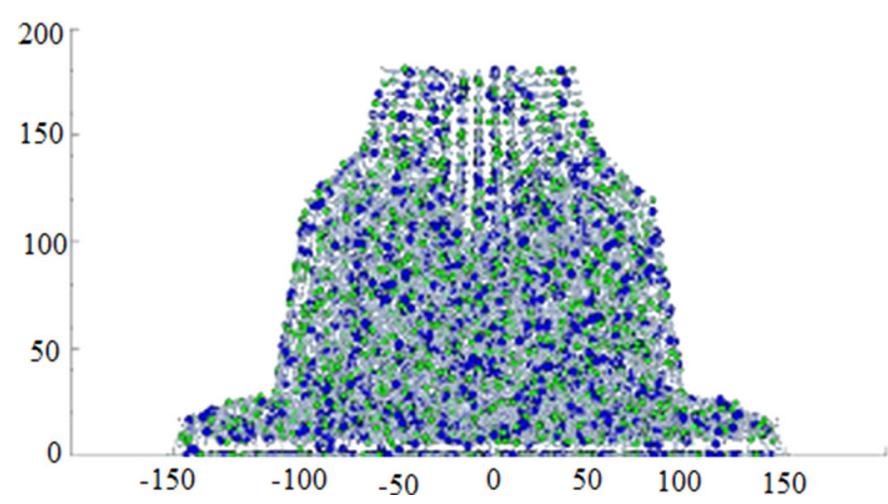

(b) (b) $\mathrm{lm} / \mathrm{s}$

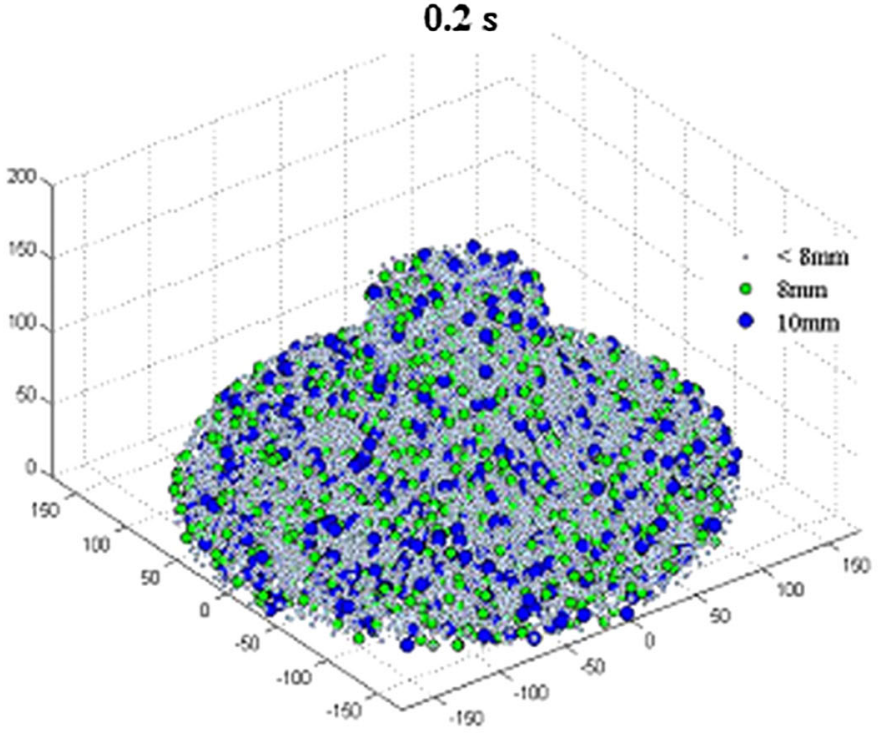

$\operatorname{lm} / \mathrm{s}$

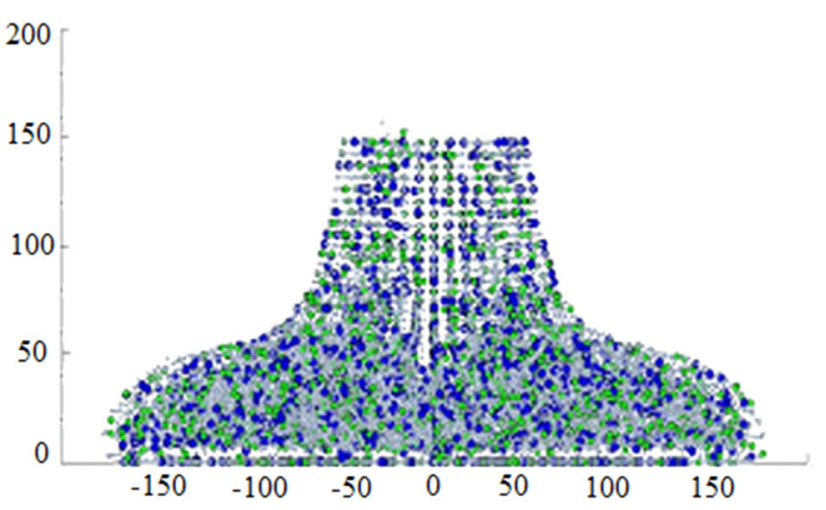

Fig. 6 Horizontal flow of SCC Mix 1 after $0.2 \mathrm{~s}$ in 3D configuration showing the large aggregates. Cone lift rate a $0.15 \mathrm{~m} / \mathrm{s}$ and $\mathbf{b} 1 \mathrm{~m} / \mathrm{s}$

Once the pressure is obtained from Eq. (10), the particle velocity is updated by the computed pressure gradient (see Eq. (7)):

$\boldsymbol{v}_{n+1}=\boldsymbol{v}_{n+1}^{*}-\left(\frac{1}{\rho} \nabla P_{n+1}\right) \Delta t$

And finally, the instantaneous particle position is updated using the corrected velocity:

$\boldsymbol{x}_{n+1}=\boldsymbol{x}_{n}+\boldsymbol{v}_{n+1} \Delta t$

The time step $\Delta t$ is chosen based on the relevant stability conditions for the given problem. In the case of Binghamtype SCC fluid flow, the time step is primarily controlled by the effective plastic viscosity. Therefore, the time step size is generally decided by:

$\Delta t=\min \left(\frac{\alpha_{1} r_{0}}{V_{\max }}, \frac{\alpha_{2} r_{0}^{2} \rho}{\mu}\right)$

where $r_{0}$ is the initial particle spacing, $V_{\max }$ is the maximum particle velocity, and $\alpha_{1}$ and $\alpha_{2}$ are the coefficients usually in order of 0.1 . These coefficients depend on the choice of SPH kernel functions and the nature of the engineering application.

\section{SPH discretisation of the governing equations}

The SPH is a Lagrangian particle-based numerical method. It was used by many researchers to solve various engineer- 
Fig. 7 Horizontal flow of SCC Mix 1 at $500 \mathrm{~mm}$ flow diameter in $3 \mathrm{D}$ configuration showing the large aggregates. Cone lift rate a $0.15 \mathrm{~m} / \mathrm{s}$ and $\mathbf{b} 1 \mathrm{~m} / \mathrm{s}$

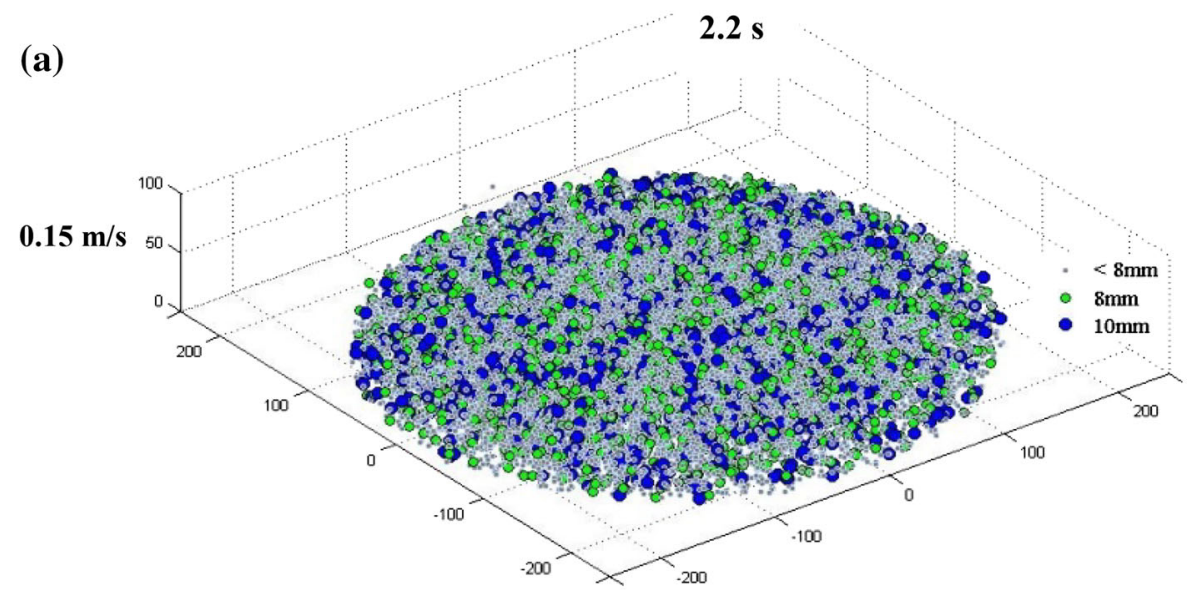

(b)

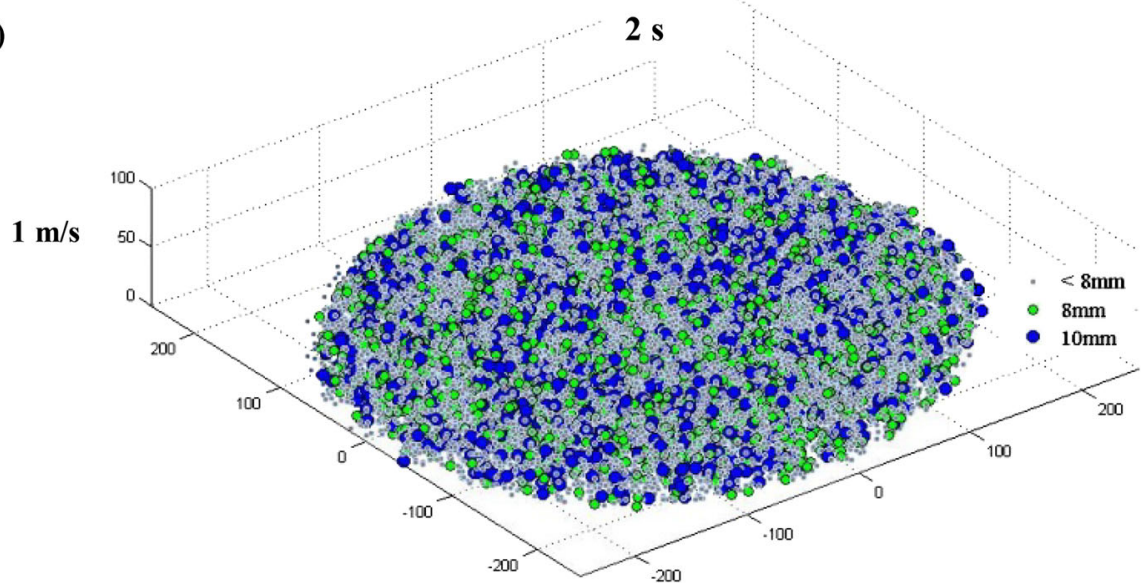

ing problems [23-30]. Due to the Lagrangian nature of SCC and large deformations and the fact that SCC contains particles of different sizes, SPH is an ideal computational method to represent with a good margin of accuracy its rheological behaviour [23]. The SPH approximation involves discretising the entire domain of the problem into a limited number of particles $N$, and then approximately calculating all the field variables on these particles. These variables and their gradients are generally interpolated from values at a discrete set of particles by using the following standard approximations:

$$
\begin{aligned}
& \phi(\boldsymbol{x})=\sum_{b=1}^{N} V_{b} \phi_{b} W_{b}(\boldsymbol{x}) \\
& \nabla \phi(\boldsymbol{x})=\sum_{b=1}^{N} V_{b} \phi_{b} \nabla W_{b}(\boldsymbol{x})
\end{aligned}
$$

Equations (14) and (15) state that the value of any function (or its differential) at any position is approximated using the average of the values of the function at all the particles within the support domain (particles $b=1,2, \ldots N$ ) of that particle weighted by the smoothing or kernel function $W_{b}(\boldsymbol{x})$.
Here, $V_{b}$ is the volume of material assigned to a given particle. For particles representing heavier and/or larger constituents in the viscous continuum, the assigned volume is equal to the ratio of actual mass to the density of continuum. The accuracy of the approximation depends on the choice of the differentiable kernel function, especially on its closeness to the Delta function.

The cubic spline function given by Eq. (16) was used in this study because of its stability, accuracy and compact support. Among many different types of kernels, research shows the tendency of bell shaped cubic spline kernel to outperform other shapes in regions of smooth data [31]

$W(\boldsymbol{x})=\frac{c}{h^{d}}\left\{\begin{array}{l}1-\frac{3}{2} \xi^{2}+\frac{3}{4} \xi^{3} \quad \text { if } \xi \leq 1 \\ \frac{1}{4}(2-\xi)^{3} \text { if } 1<\xi \leq 2 ; \quad \xi=\frac{\|x\|}{h} \\ 0 \text { if } \xi>2\end{array}\right.$

where $d$ is the number of dimensions of the problem, $c$ is a scaling factor to normalize the kernel function, and $h$ the length parameter which has a similar interpretation to the element size in the finite element method. 
Fig. 8 Horizontal flow of SCC Mix 1 after $17 \mathrm{~s}$ in 3D configuration showing the large aggregates. Cone lift rate (a) $0.15 \mathrm{~m} / \mathrm{s}$ and (b) $1 \mathrm{~m} / \mathrm{s}$
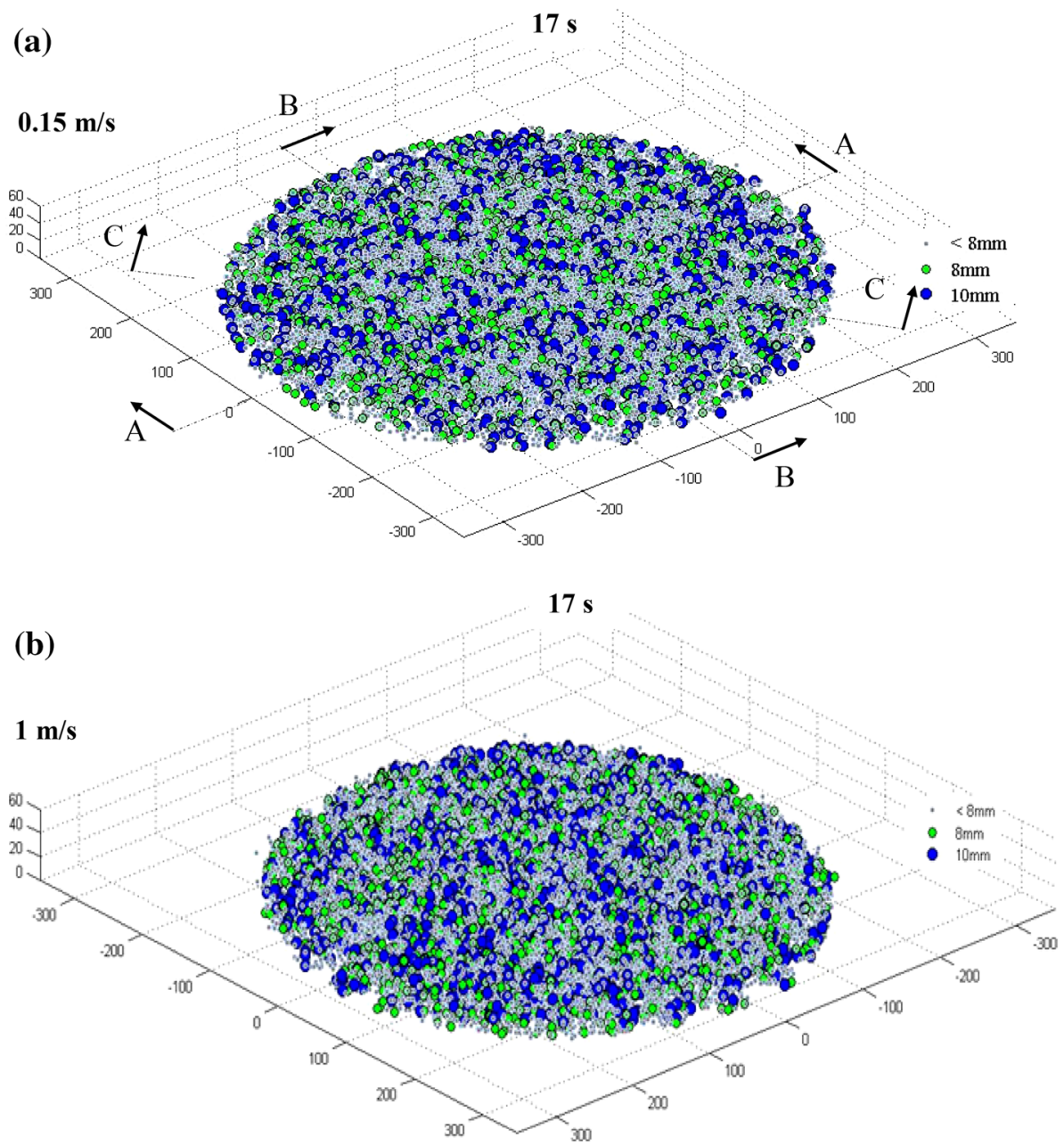

Fig. 9 Diametrical cross-sections a-c of slump flow after $17 \mathrm{~s}$ for Mix 1
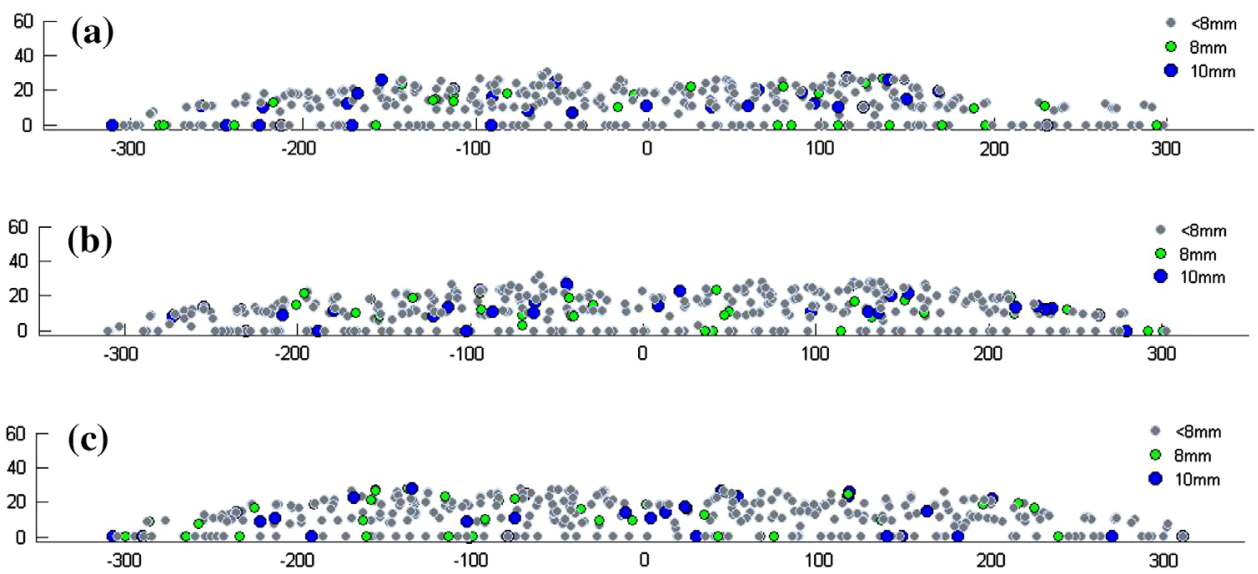

The standard SPH approximations as given by Eq. (14) and (15) do not accurately reproduce or approximate the function $\phi(x)$ and $\nabla \phi(x)$. Therefore corrected SPH equations were developed to address these issues [32]. For instance, the cor- rected form of the gradient of the velocity at a given point ' $a$ ' is given by,

$\nabla \boldsymbol{v}_{a}=\sum_{b \in M_{a}} V_{b} \boldsymbol{v}_{b} \otimes \tilde{\nabla} \tilde{W}_{b}\left(\boldsymbol{x}_{a}\right)$ 
(a)

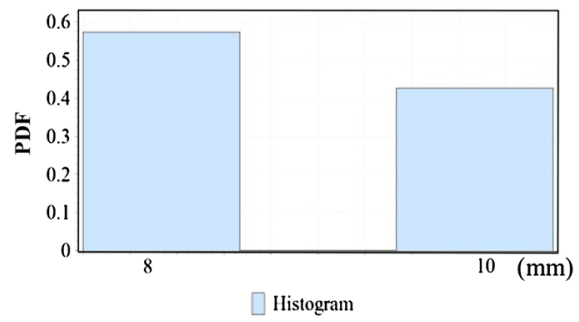

(b)

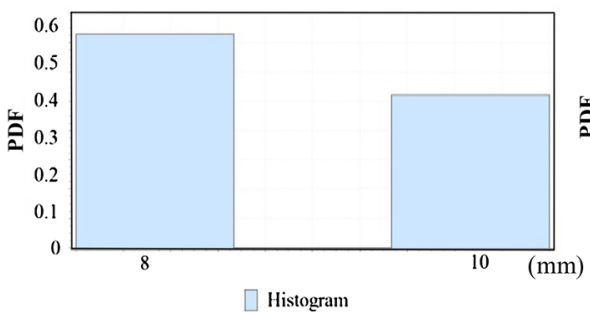

(c)

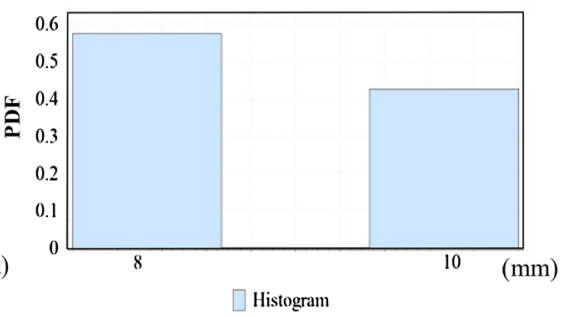

Fig. 10 Histogram of larger aggregate distribution ( $\geq 8 \mathrm{~mm})$ in Mix 1 along several diametrical cross-sections a-c after $17 \mathrm{~s}$ flow time in the slump test

where $\tilde{W}$ indicates that the kernel function is corrected to satisfy the consistency conditions [32,33], $b$ is the neighbouring particle within the support domain $M_{a}$, and $\tilde{\nabla}$ above indicates that the gradient is corrected to reproduce linear consistency. The gradient correction used here is adopted from the mixed kernel and gradient correction, discussed in [33].

Now adopting the corrected SPH interpolation procedures, all the relevant equations can be formulated into SPH approximations. Three terms in the mass and momentum conservation equations need to be defined in the SPH formulation:

The divergence of velocity in Eq. (3) can be written as,

$$
(\nabla \cdot \boldsymbol{v})_{a}=\sum_{b=1}^{N} V_{b} \boldsymbol{v}_{b} \cdot \tilde{\nabla} \tilde{W}_{b}\left(\boldsymbol{x}_{a}\right)
$$

where $a$ and $b$ are the reference particle and its neighbour, respectively. In the above equation $\tilde{\nabla} \tilde{W}$ is the corrected gradient of the corrected kernel

The gradient of pressure in Eq. (4) can be described by,

$\nabla P_{a}=\sum_{b=1}^{N} V_{b} P_{b} \tilde{\nabla} \tilde{W}_{b}\left(\boldsymbol{x}_{a}\right)$

Hence, the Laplacian in the pressure Poisson Eq. (10) can be formulated using the divergence and gradient operators of the SPH formulation to give:

$$
\sum_{b \in M_{a}} V_{b} V_{a} \nabla P_{b} . \tilde{\nabla} \tilde{W}_{a}\left(\boldsymbol{x}_{b}\right)=\frac{\rho_{a}}{\Delta t} \sum_{b \in M_{a}} V_{b} \boldsymbol{v}_{b} . \tilde{\nabla} \tilde{W}_{b}\left(\boldsymbol{x}_{a}\right)
$$

The above pressure equation can be solved using any suitable iterative method. In the present implementation a preconditioned conjugate gradient method is used. In addition to the numerical procedure and governing equations described above, a suitable method to treat the boundary conditions has to be developed.
Table 3 Volume fraction of fibres in Mixes 2 and 4, the number of particles representing them and their assigned volumes

\begin{tabular}{lll}
\hline & Mix 2 & Mix 4 \\
\hline Total number of particles & 23,581 & 23,581 \\
Volume fraction of fibres (\%) & 0.5 & 2.5 \\
Number of fibres & 118 & 590 \\
Number of fibre end particles & 236 & 1180 \\
Assigned volume/particle $\left(\mathrm{mm}^{3}\right)$ & 366.20 & 381.52 \\
\hline
\end{tabular}

\section{Initial configuration and boundary conditions}

When solving the momentum and the continuity equations, appropriate initial and boundary conditions need to be applied. Three types of boundary conditions need to be considered in the simulation of slump cone test; a zero pressure condition on the free surface, Dirichlet boundary condition at the wall of the cone, and Neumann conditions on the pressure gradient (this zero pressure gradient is used only for solving the pressure Poisson equation), as illustrated in Fig. 3. The initial conditions depend on how fast the cone filled with the SCC mix is lifted and the mix discharged on to the base plate. Two rates of cone lift will be considered; 0.15 and $1 \mathrm{~m} / \mathrm{s}$. The part of the mix not in contact with the cone surface during the lifting of the cone is a free surface with $P=0$, but the part in contact is subject to sliding frictional resistance (Fig. 3d).

Four arrays of rigid dummy particles placed outside the wall of the cone were used to implement the wall boundary conditions with space $r_{o}$ between the arrays, where $r_{o}$ is the initial particle spacing. To represent the sliding frictional resistance boundary conditions along the cone wall and the bottom plate, a dynamic coefficient of friction between the SCC mix and steel equal to $0.55 \mathrm{Ns} / \mathrm{m}$.

\section{Treatment of aggregates}

An essential requirement of a SCC mix is that heavier aggregate particles do not segregate from the paste during the flow. To investigate this, all aggregates larger than or equal to $8 \mathrm{~mm}$ 

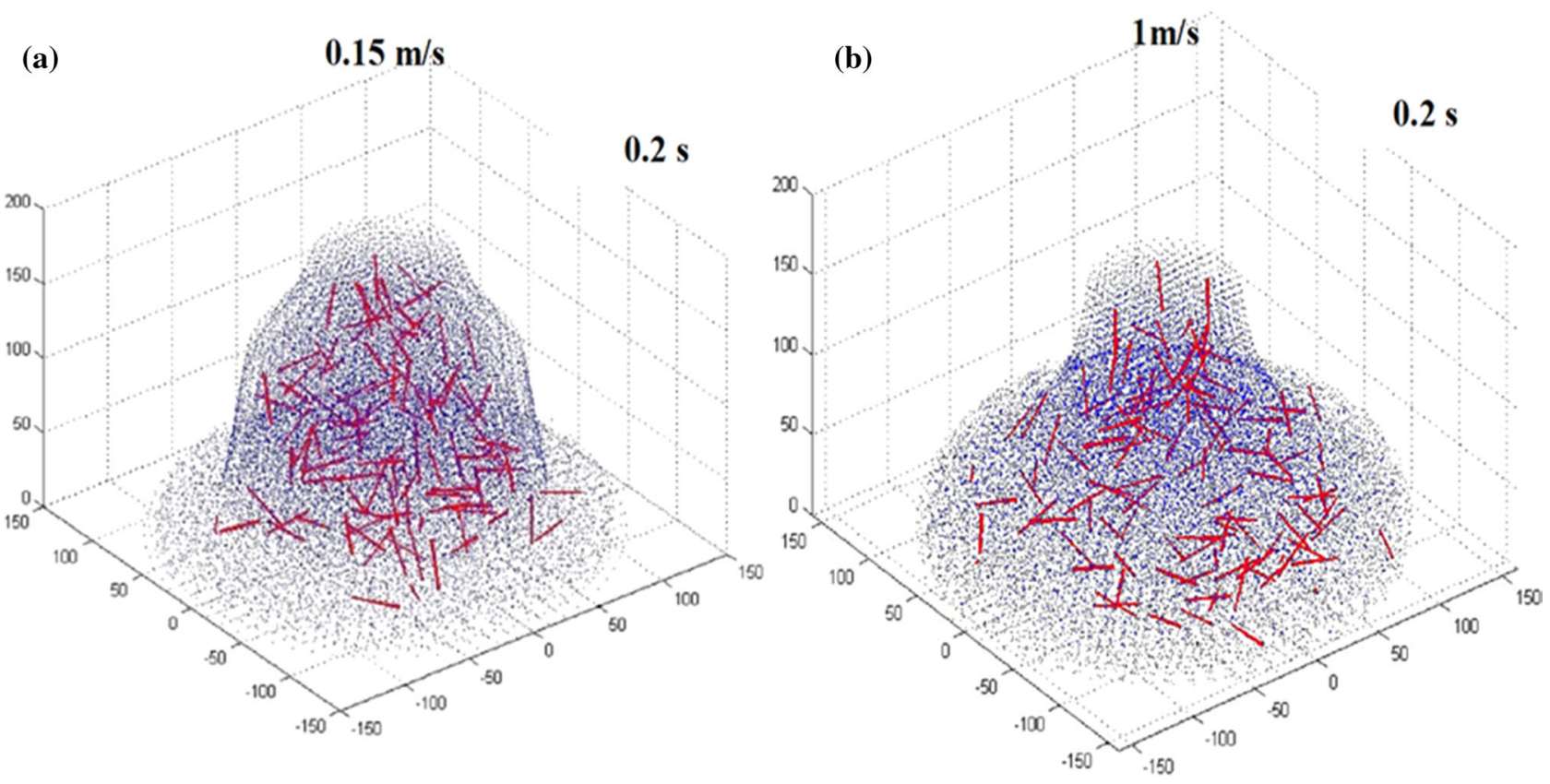

(a)

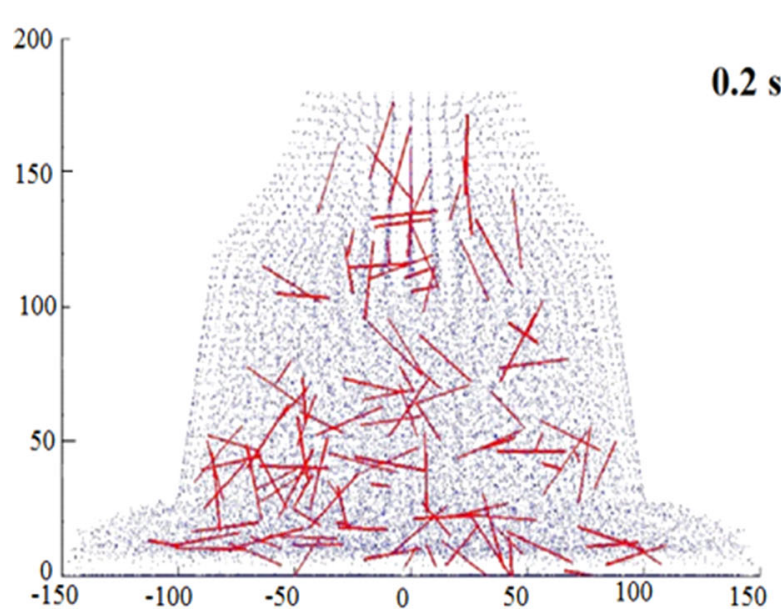

(b)

$1 \mathrm{~m} / \mathrm{s}$

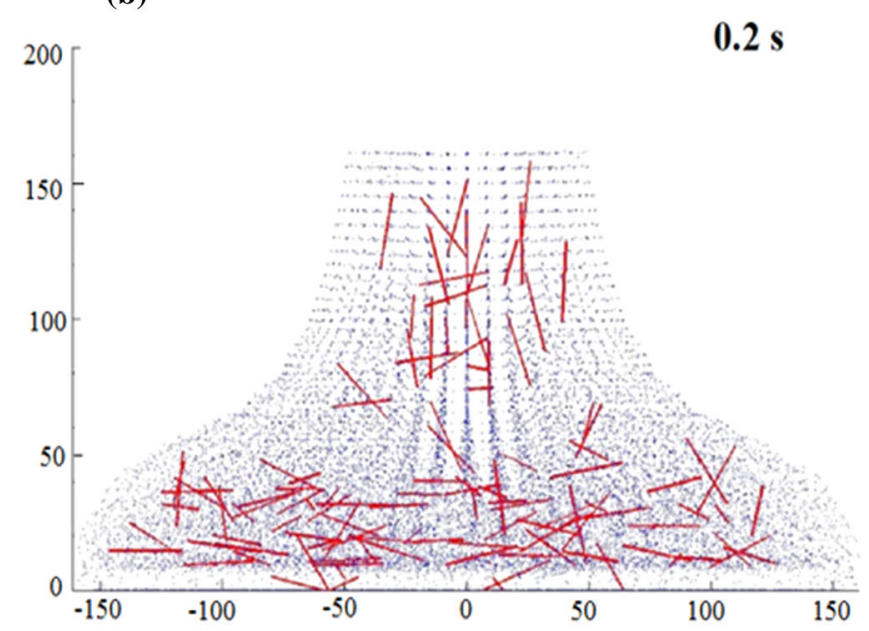

Fig. 11 Horizontal flow of Mix 2 in 3D configuration after $0.2 \mathrm{~s}$. Cone lift rate a $0.15 \mathrm{~m} / \mathrm{s}, \mathbf{b} 1 \mathrm{~m} / \mathrm{s}$

in size have been modelled as separate particles suspended in the viscous paste containing the remaining particles less than $8 \mathrm{~mm}$ in size.

Sieve analysis was first performed to determine the grading curve of aggregate particle sizes within a given sample. According to the sieve analysis of the Mix 1 (Table 1), the volume fractions of aggregates 10 and $8 \mathrm{~mm}$ in size were 15 and $11 \%$, respectively (Table 2). (The volume fractions were calculated from the measured mass fractions). The volume fraction of particles less than $8 \mathrm{~mm}$ in size which form the paste was therefore $74 \%$.

The number of particles used to represent the volume of cone contents sets a lower limit on the volume element that can be distinguished from the homogeneous mass, i.e. the resolution of the modelling technique. In the simulations below, a total of 23,581 particles have been used to represent the volume of mix in the cone $\left(5.498 \times 10^{6} \mathrm{~mm}^{3}\right)$ giving a resolution of $233.15 \mathrm{~mm}^{3}$ if all particles have the same density as the viscous continuum. The resolution may be somewhat different if the particles have different densities (see Table 2 below). Thus, in Mix 1 the large aggregates that can be distinguished from the homogeneous mass must have a volume exceeding this minimum. It is for this reason that only the aggregates of size $8 \mathrm{~mm}$ and above have been chosen.

In order to be able to monitor the velocity vectors and positions of aggregates of different sizes, as well as those 
Fig. 12 Horizontal flow of Mix 2 in 3D configuration after $3 \mathrm{~s}$. Cone lift rate a $0.15 \mathrm{~m} / \mathrm{s}, \mathbf{b} 1 \mathrm{~m} / \mathrm{s}$
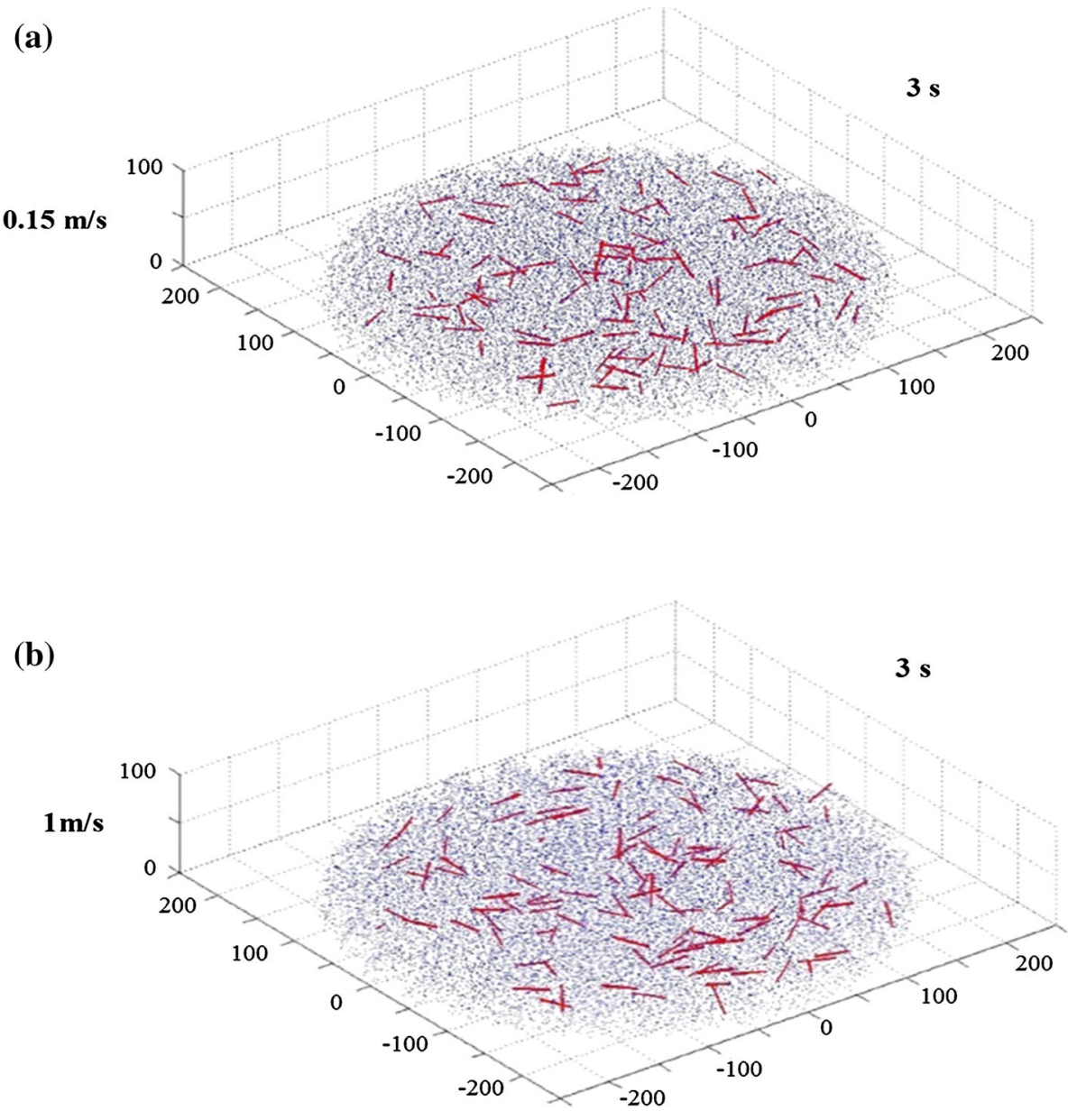

of the fluid particles representing the paste, the particles are represented by distinct colours as shown in Fig. 4.

Further, the following steps were taken during the numerical simulations.

- All particles representing the mix were generated randomly.

- Particles representing the paste as well as the large aggregates form a homogeneous mass and have the same continuum properties except for their assigned volumes.

- The masses of the SPH particles representing the various aggregate particles in the SCC mix were calculated based on their respective volume fractions in the mix.

- Particles representing the large aggregates according to their assigned volumes were tagged (and colour coded as shown above) throughout the simulation in order to monitor their velocity vectors and positions.

\section{Teatment of fibres}

A number of computational modelling strategies have been attempted to model the distribution of fibres and their orienta- tion during the flow. For instance, numerical techniques such as the discrete element method [34] or the lattice Boltzmann technique [35] can be used to model the SCC fluid flow with fibre suspensions. These numerical techniques or computational methodologies have their own merits and drawbacks in solving SCC flow with suspended fibres. However, it would seem natural, simpler and more appropriate to use meshless particle based Lagrangian numerical techniques to simulate the flow and to monitor the distribution of fibres and their orientation during the flow.

The fibre dynamics in the viscous SCC is captured separately by using Russell's slender body approximation. According to this approximation, the resistance to the free translational and rotational motion of a slender body in a viscous fluid is given by the force vector $\boldsymbol{F}=\zeta \boldsymbol{d}$ in terms of the rate of deformation vector $\boldsymbol{d}$, with $\zeta=\frac{2 \pi \eta l}{\ln \left(2 l_{d}\right)}$. Here, $l$ is the length of the slender body, $l_{d}$ its aspect ratio, and $\eta$ is the viscosity of the fluid without fibres. Next, a random distribution of fibres of equal length in the viscous fluid is considered and an ensemble average (replaced by a volume average for uniform random distribution) of these force vectors in the viscous liquid-fibre suspension performed to calculate the 
Fig. 13 Horizontal flow of Mix 2 in 3D configuration after $17 \mathrm{~s}$. Cone lift rate a $0.15 \mathrm{~m} / \mathrm{s}, \mathbf{b} 1 \mathrm{~m} / \mathrm{s}$ (a)
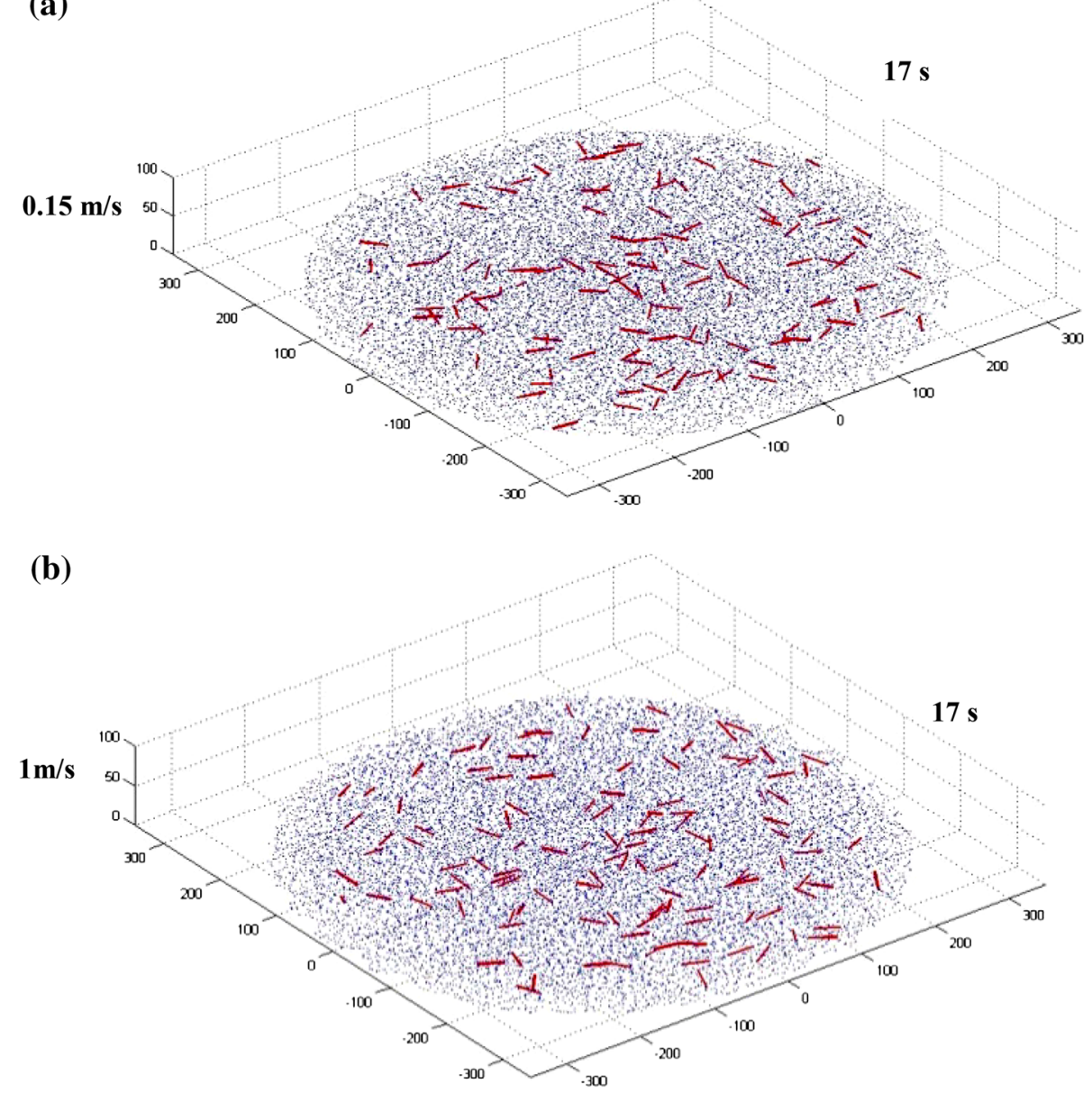

shear stress versus rate of deformation relation of an equivalent isotropic viscous fluid-fibre mixture. In this manner, the fibre motion in the viscous liquid is captured through an increase in the viscosity of the equivalent viscous liquid with fibres in it. Details may be found in [9]. This viscosity is given by Eq. (1)

As the effect of fibre motion on the flow field has been captured through an increase in the viscosity of the liquidfibre suspension, the fibres can be treated simply as passive markers that move and orient according to the fluid motion. This is an important advantage of the SPH methodology proposed by Kulasegaram and Karihaloo [36] for monitoring the fibres during the flow.

The key points of this methodology as shown in Fig. 5 are the following.

- There are two particles that represent the ends of a fibre. These particles are imagined to be connected by a virtual rigid link. The assigned volume of the fibre is equally divided between them. These particles are tagged throughout the simulation process and the distance between them is maintained equal to the fibre length.
- Both fibre and fluid particles behave as a homogeneous mass and have the same continuum properties except their assigned volumes.

- Fibre end particle position is mainly dictated by the fluid flow of the homogeneous SCC. It is therefore feasible to assume that the positions of the fibre end particles are largely controlled by the fluid particles surrounding them.

- Fibres are generated randomly, maintaining a constant distance between their ends equal to the fibre length $\mathrm{L}_{0}$. The distance $\mathrm{L}_{n+1}$ at a subsequent time step $\mathrm{t}_{n+1}$ between the particles representing the ends of a fibre was calculated and forced to be equal to $\mathrm{L}_{0}$ within an acceptable error.

The key steps involved in enforcing the constant distance between the pair of particles representing a fibre can be summarised as follows [36], once the particle positions are updated using Eq. (12) from time step $t_{n}$ to $t_{n+1}$,

Step 1: Check whether the distance $\left(\mathrm{L}_{\mathrm{n}+1}\right)$ between the pair of particles representing each and every fibre is equal to the fibre length $\left(\mathrm{L}_{0}\right)$ within an acceptable error.

Step 2: If $\left|\mathrm{L}_{n+1}-\mathrm{L}_{0}\right|>10^{-5}$ for a certain fibre, then equal and opposite penalty forces $F_{P}$ proportional to 

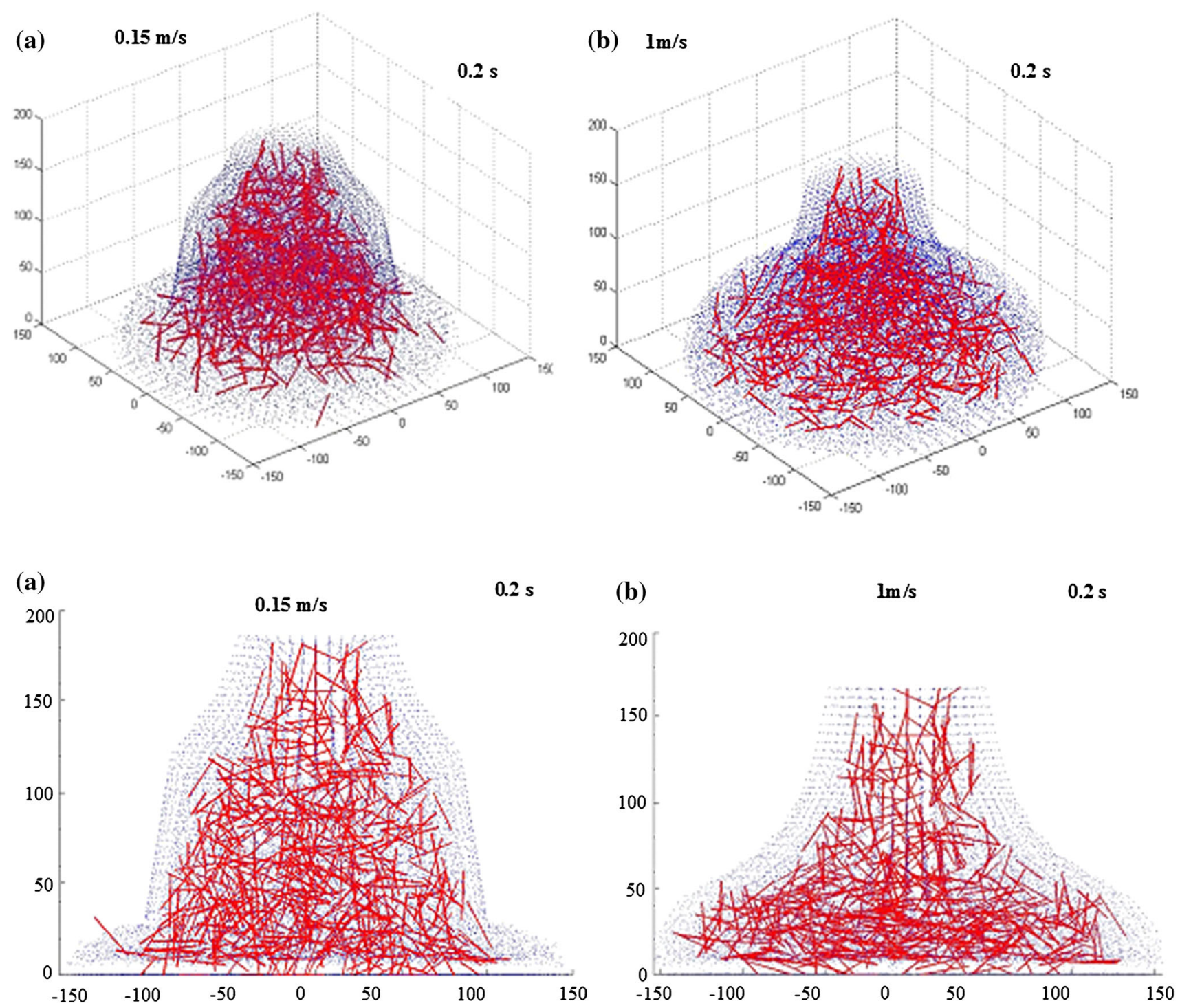

Fig. 14 Horizontal flow of Mix 4 in 3D configuration after $0.2 \mathrm{~s}$. Cone lift rate a $0.15 \mathrm{~m} / \mathrm{s}, \mathbf{b} 1 \mathrm{~m} / \mathrm{s}$

$\left|\mathrm{L}_{n+1}-\mathrm{L}_{0}\right|$ are introduced in Eq. (6) on the pair of particles representing that fibre along the vector connecting this pair of particles.

Step 3: The Eqs. $(6,7,10,11,12)$ are now solved again sequentially to determine the positions of all the particles. Step 4: Steps 1 to 3 are repeated until the pairs of particles representing all the fibres satisfy the condition $\left|L_{n+1}-L_{0}\right|<10^{-5}$.

Based on the formulation detailed above, suitable numerical schemes which integrate the Lagrangian SPH approximations of the governing equations with the rheological Bingham type model for SCC have been developed. These numerical schemes have been utilised to understand the behaviour of SCC flow containing (a) coarse aggregate particles of various sizes, and (b) short steel fibres.

\section{Simulation results}

\subsection{Slump cone test for SCC mixes without fibres}

In this section, 3D numerical simulations of the slump cone test of a typical SCC mix (Mix 1, Table 1) are presented to investigate its flow characteristics and compared with the test results. These simulations highlight the distribution of the large aggregates in this mix (larger than or equal to $8 \mathrm{~mm}$ ) in order to check whether these heavier aggregates stay homogenously distributed in the viscous mix at all times during the flow. The plastic viscosity of the SCC mix was first calculated using the micromechanical model proposed in [9] from the known plastic viscosity of the cement paste and the volume fractions of the various second phase particles (Table 1). As mentioned above, the yield stress of SCC is 
Fig. 15 Horizontal flow of Mix 4 in 3D configuration after $3 \mathrm{~s}$. Cone lift rate a $0.15 \mathrm{~m} / \mathrm{s}, \mathbf{b} 1 \mathrm{~m} / \mathrm{s}$
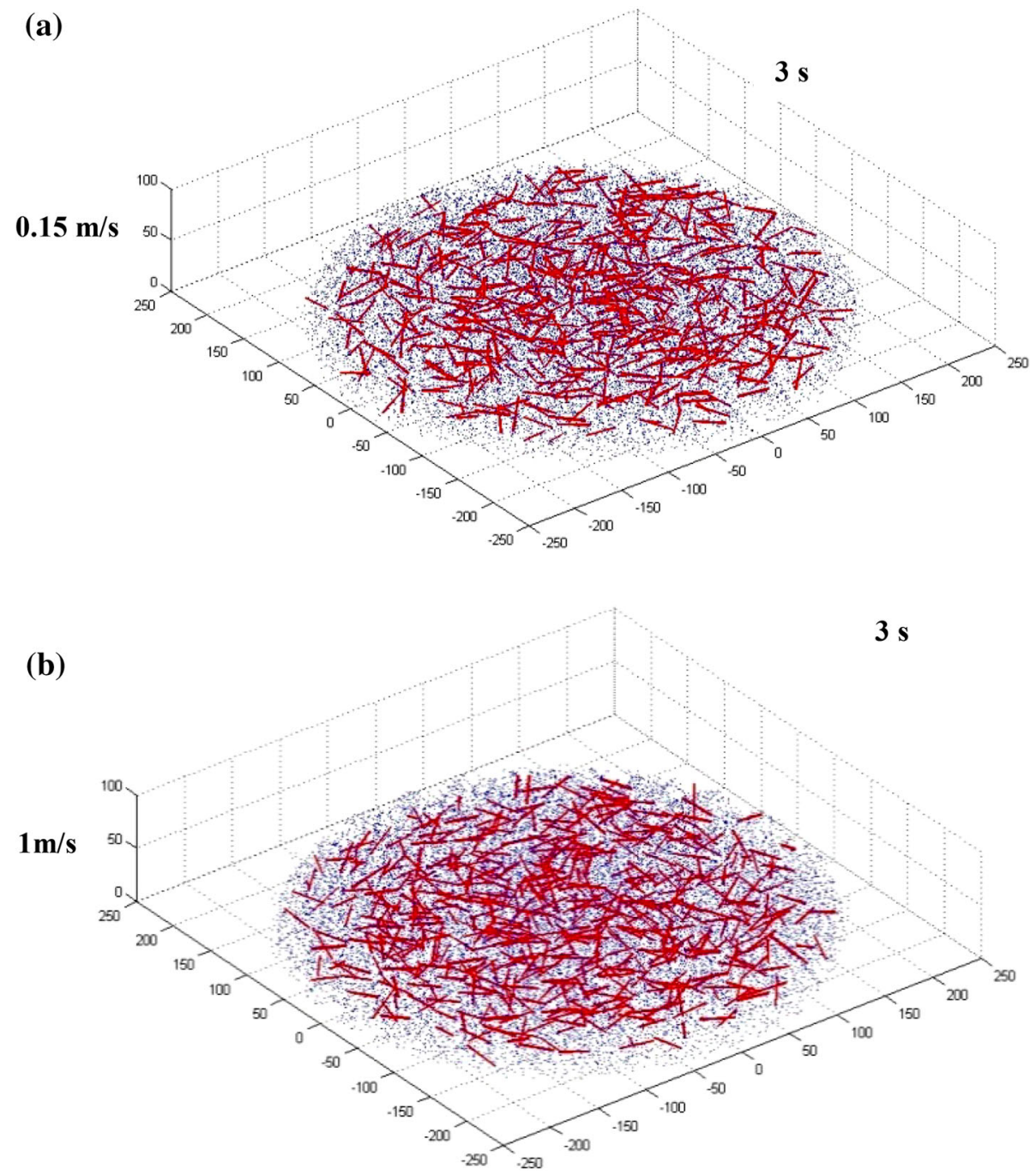

low (200 Pa) and practically constant over a wide range of plastic viscosities [37].

In the 3D simulations the volume of the mix in the cone was simulated by 23,581 particles. Two simulations were performed; one in which the cone was lifted at a slow speed equal to $0.15 \mathrm{~m} / \mathrm{s}$, and the second in which the cone was lifted at a quicker rate equal to $1 \mathrm{~m} / \mathrm{s}$. All the material parameters of the mix, namely the yield stress, the plastic viscosity are those of Mix 1 in Table 1. The results of these simulations are shown in Figs. 6, 7 and 8.

It can be observed from the simulations illustrated in Figs. 6, 7 and 8, that the larger aggregates do indeed stay homogenously distributed in the mix at all times during the flow. The flow spread to a diameter of $500 \mathrm{~mm}$ in $2.2 \mathrm{~s}$, exactly as in the in the slump cone test in the laboratory. Equally importantly, the surface of the spread after $2.2 \mathrm{~s}$ looks smooth as a 'pan cake' identical to that observed in the laboratory test on this mix (Mix 1, Fig. 1). The only free variable that we altered in the simulation to get this exact fit was the dynamic coefficient of friction between the SCC mix and steel of the cone wall and of the base plate. The value which gave this excellent agreement with the test result was equal to $0.55 \mathrm{Ns} / \mathrm{m}$.

The speed of lifting the cone does indeed affect the shape of the slump at early stage of flow (at $0.2 \mathrm{~s}$ flow time as seen in Fig. 6). A slightly larger flow diameter associated with the higher speed of lift was observed at the initiation of the flow; however, the effect of the lifting rate on the flow diameter diminishes after a few seconds of flow time.

By cutting the simulated slump flow by diametrical planes (A, B and C as illustrated above in Fig. 8a) after $17 \mathrm{~s}$ flow time, the statistics of the large aggregates $(\geq 8 \mathrm{~mm})$ along these sections can be investigated.

Figure 9 shows how the aggregates are distributed in the diametrical cross-sections after $17 \mathrm{~s}$ flow time with no visible settlement of the larger aggregates $(\geq 8 \mathrm{~mm})$.

That the larger aggregates are indeed distributed in an identical manner along these three sections can be ascer- 
Fig. 16 Horizontal flow of Mix 4 in 3D configuration after $17 \mathrm{~s}$. Cone lift rate a $0.15 \mathrm{~m} / \mathrm{s}, \mathbf{b} 1 \mathrm{~m} / \mathrm{s}$
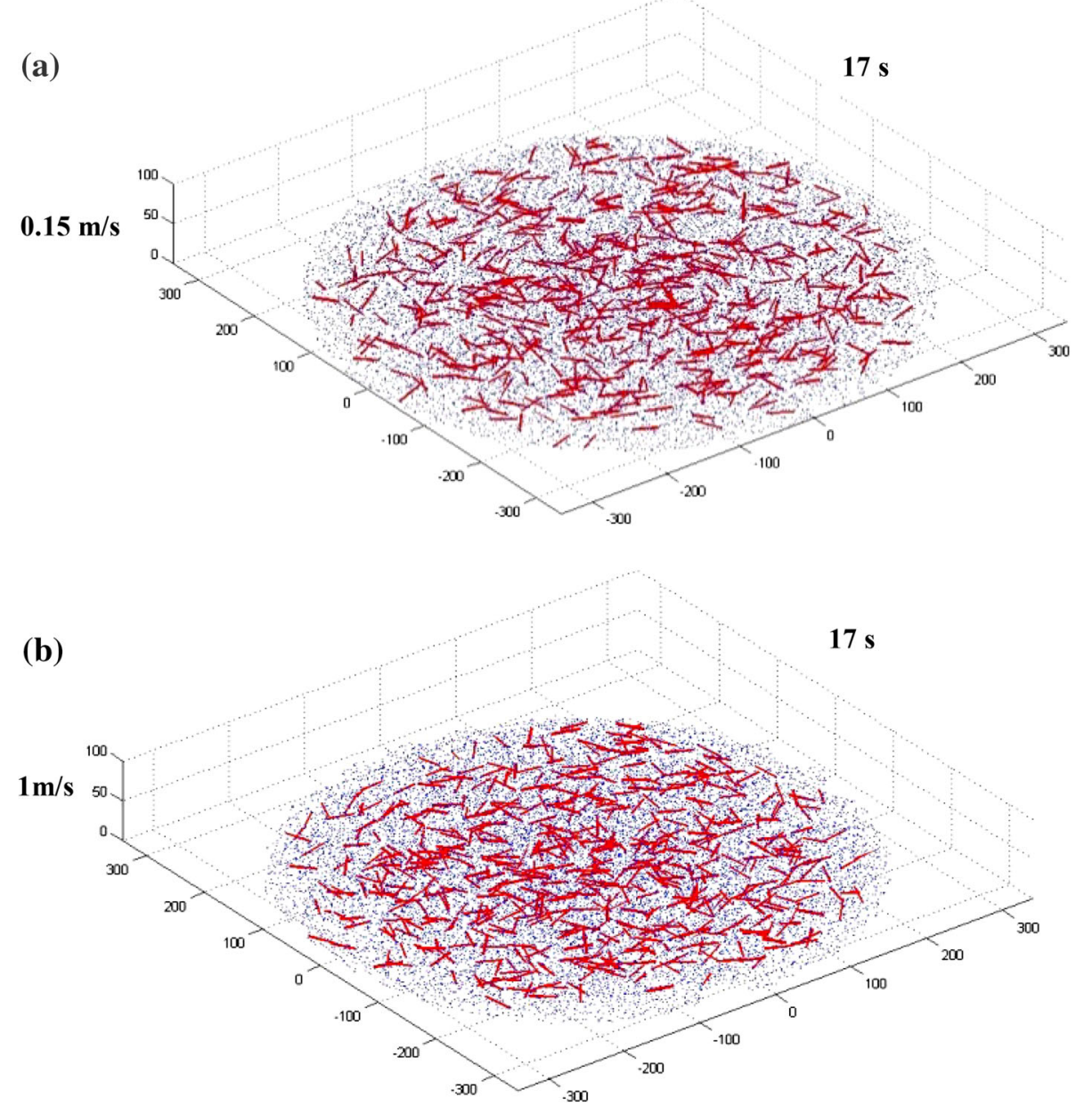

tained by performing a statistical analysis of these aggregates to estimate the best fit probability density function (PDF) which in this case turns out to be the Weibull distribution function amongst the many distribution functions that were tried. It can be seen from the histograms in Fig. 10 that the larger aggregate distribution is almost identical along the three cross-sections (Fig. 8a).

Here, the simulation was stopped at $17 \mathrm{~s}$ because of the excessive computational time involved. It should however be noted that the mix itself has not yet stopped flowing; it has only spread to a diameter of just over $600 \mathrm{~mm}$ after $17 \mathrm{~s}$, whereas it will only stop to flow when this diameter is $805 \mathrm{~mm}$ (see, Mix 1, Table 1).

\subsection{Slump cone test for mixes with fibres}

To investigate how the short steel fibres will distribute and orient themselves during the flow, the slump cone tests of two mixes with fibres (Mixes 2 and 4 in Table 1) were simulated. In these simulations, the total number of particles used was also 23,581. The short steel fibres were treated as explained above. The number of fibres in each of these mixes was calculated from their volume fraction $(0.5 \%$ in Mix 2 and $2.5 \%$ in Mix 4) (see Table 3). The plastic viscosity of these mixes is of course much higher than that of mixes without fibres (see Table 1). Apart from the different plastic viscosities of the mixes, their yield stress (200 Pa) and the dynamic coefficient of friction with the steel wall of the cone and the base plate $(0.55 \mathrm{Ns} / \mathrm{m})$ are the same as for an SCC mix without fibres.

Figures 11, 12, 13, 14, 15 and 16 show the distribution of fibres and their orientation during the flow of Mixes 2 and 4, respectively. The time for the mixes to spread to a diameter of $500 \mathrm{~mm}\left(\mathrm{t}_{500}=3 \mathrm{~s}\right)$ matches exactly the time measured in the laboratory (Table 1). The surface of the spread is smooth and the fibres stay homogeneously distributed at all times during the flow.

Again, the simulations of both mixes were performed at two different rates of the cone lift, 0.15 and $1 \mathrm{~m} / \mathrm{s}$.

A two-dimensional or axisymmetric simulation of these mixes would be misleading because it would show all the fibres in a single plane. The three-dimensional flow simulation which shows the actual distribution of fibres and their 
orientation during the flow gives a highly accurate picture of their rigid body motion.

It can be seen from Figs. 11, 12, 13, 14, 15 and 16 that the speed of lifting the cone does also affect the shape of the slump at early stage of flow (at 0.2 s flow time as seen in Figs. 11 and 14). However, the difference in the flow diameters at the two rates is negligible.

The proposed method can be effectively applied in the numerical simulation of SCC flow to analyse the filling behaviour of these highly viscous fluids. The numerical results confirm that the $3 \mathrm{D} \mathrm{SPH}$ methodology is capable of predicting accurately the flow of SCC with and without fibres.

In the numerical simulations presented for both SCC with coarse aggregates and SCC with fibres, the total number of SPH nodal particles used was 23,581. This number of particles was chosen to obtain the results with adequate accuracy in a reasonable time. These simulations were carried out on a PC with $2 \mathrm{GHz}$ (XP850 Intel Core CPU) processor and the time taken for simulating the flow of SCC with homogeneous mass distribution or with various coarse aggregates for $2.2 \mathrm{~s}$ was approximately $40 \mathrm{~h}$. In the case of SCC flow with fibres the time taken for simulating the flow for $3 \mathrm{~s}$ was approximately $65 \mathrm{~h}$. The time taken for the simulation of SCC flow with fibres was longer than that of SCC with coarse aggregate particles by $15-20 \%$. This is due to the iterative computation performed in the simulation of SCC flow with fibres to enforce the constant fibre length between particles representing fibre end points. In the numerical simulations shown above, to ensure that the front of the SCC flow has a smooth profile, the velocities of the particles obtained by Eq. (11) were smoothed by the following equation

$\overline{\boldsymbol{v}}\left(\boldsymbol{x}_{a}\right)=\sum_{b=1}^{N} V_{b} \boldsymbol{v}_{b} W_{b}\left(\boldsymbol{x}_{a}\right)$

where $\overline{\boldsymbol{v}}\left(\boldsymbol{x}_{a}\right)$ is the smoothed velocity of particle ' $a$ '. This velocity was then used in Eq. (12) to calculate the updated position of particle ' $a$ '. In a similar manner all the particle velocities and positions were smoothed and updated. This smoothing procedure also adds to the total computational time taken by the numerical simulations.

\section{Conclusions}

A corrected Lagrangian SPH method has been used to simulate the flow of SCC mixes of varying strengths and performance, some of which contain short steel fibres. A suitable Bingham model [4] has been coupled with the Lagrangian momentum conservation and continuity equations to model the flow. The mix characteristics of the SCC mix have been fully incorporated implicitly through the plastic viscosity, which has been calculated using the micromechanical model described in [9].

The simulation of SCC mixes without fibres followed the distribution of aggregates of different sizes ( 8 and $10 \mathrm{~mm}$ ) throughout the flow, while those of the SCC mixes with fibres focused on the distribution of fibres and their orientations during the flow. A comparison between the experimental and the simulation results is very encouraging. The developed numerical methodology is able to capture the flow behaviour of SCC mixes and to provide insight into the distribution of large aggregates and of fibres and their orientations during the flow.

The lengthy computational time that the SPH simulations take can be regarded as a weakness of the SPH method. But it can be significantly reduced either by using high specification serial computers or by using high performance parallel computers. Since the particle methods such as SPH method are eminently suited for parallelisation, larger 3D configurations can be simulated within a reasonable computational time by the developed algorithms after appropriately parallelising them.

\section{References}

1. Wu J, Shu C (2010) An improved boundary-lattice Boltzmann method for simulating three-dimensional incompressible flows. $\mathrm{J}$ Comput Phys 229:5022-5042

2. Baaijens FPT (2001) A fictitious domain/mortar element method for fluid-structure interaction. Int J Numer Methods Fluids 35:743761

3. Deeb R, Ghanbari A, Karihaloo BL (2012) Development of selfcompacting high and ultra- high performance concretes with and without steel fibres. Cem Concr Compos 34:185-190

4. Kulasegaram S, Karihaloo BL, Ghanbari A (2011) Modelling the flow of self-compacting concrete. Int J Numer Anal Methods Geomech 35:713-726

5. Deeb R, Karihaloo BL (2013) Mix proportioning of selfcompacting normal and high strength concretes. Mag Concr Res 65:546-556

6. The European Guidelines for Self-Compacting Concrete Specification, Production and Use (2005). www.efnarc.org. Accessed 29 Nov 2012

7. Interim Guidelines for the Use of Self-Consolidating Concrete in Precast/Prestressed Concrete Institute (2003). www.pci.org. Accessed 29 Nov 2012

8. Grünewald S, Walraven JC (2003) Rheological measurements on self-compacting fibre reinforced concrete. In Proceedings of the $3 \mathrm{rd}$ International RILEM Symposium on Self-Compacting Concrete. eds. Wallevik Ó. and Níelsson I. S.A.R.L France 49-58

9. Ghanbari A, Karihaloo BL (2009) Prediction of the plastic viscosity of self-compacting steel fibre reinforced concrete. Cem Concr Res 39:1209-1216

10. Phan-Thien N, Huilgol RR (1980) A micromechanic theory of chopped-fibre-reinforced materials. J Fibre Sci Technol 13:423433

11. Krieger IM, Dougherty TJ (1959) A mechanism for non-Newtonian flow in suspensions of rigid spheres. J Rheol 3:137-152

12. Frankel NA, Acrivos A (1967) On the viscosity of a concentrated suspension of solid spheres. Chem Eng Sci 22:847-853 
13. Chong JS, Christiansen EB, Baer AD (1971) Rheology of concentrated suspensions. J Appl Polym Sci 15:2007-2021

14. de Kruif CG, Van Iersel EMF, Vrij A, Russel WB (1985) Hard sphere colloidal dispersions: viscosity as a function of shear rate and volume fraction. J Chem Phys 20:4717-4725

15. Heirman G, Vandewalle L, Van Gemert D, Wallevik Ó (2008) Integration approach of the Couette inverse problem of powder type self-compacting concrete in a wide-gap concentric cylinder rheometer. J Nonnewton Fluid Mech 150:93-103

16. Sun Z, Voigt T, Shah SP (2006) Rheometric and ultrasonic investigations of viscoelastic properties of fresh Portland cement pastes. Cem Concr Res 36:278-287

17. Grzeszczyk S, Lipowski G (1997) Effect of content and particle size distribution of high-calcium fly ash on the rheological properties of cement pastes. Cem Concr Res 27:907-916

18. Nehdi M, Rahman MA (2004) Estimating rheological properties of cement pastes using various rheological models for different test geometry, gap and surface friction. Cem Concr Res 34:1993-2007

19. Papanastasiou TC (1987) Flows of materials with yield. J Rheol 31:385-404

20. Chorin AJ (1968) Numerical solution of the Navier-Stokes equations. Math Comput 22:745-762

21. Cummins SJ, Rudman M (1999) An SPH projection method. J Comput Phys 152:584-607

22. Koshizuka S, Nobe A, Oka Y (1998) Numerical analysis of breaking waves using moving particle semi-implicit method. Int J Numer Methods Fluids 26:751-769

23. Liu GR, Liu MB (2003) Smooth particle hydrodynamics. World Scientific Printers CO. Pte. Ltd., Singapore. ISBN 981-238-456-1

24. Lucy LB (1977) A numerical approach to the testing of the fission hypothesis. Astron J 82:1013-1024

25. Gingold RA, Monaghan JJ (1977) Smoothed particle hydrodynamics: theory and application to non-spherical stars. Mon Not R Astron Soc 181:375-389
26. Morris JP, Fox PJ, Zhu Y (1977) Modelling low Reynolds number incompressible flows using SPH. J Comput Phys 136:214-226

27. Shao S, Lo EYM (2003) Incompressible SPH method for simulating Newtonian and non-Newtonian flows with a free surface. Adv Water Resour 26:787-800

28. Takeda H, Miyama SM, Sekiya M (1994) Numerical simulation of viscous flow by smoothed particle hydrodynamics. Progress Theoret Phys 92:939-960

29. Welton W (1998) Two-dimensional PDF/SPH simulation of compressible turbulent flows. J Comput Phys 139:410-443

30. Dilts GA (2000) Moving least square particle hydrodynamics II: conservation and boundaries. Int J Numer Methods Eng 48:15031524

31. Fulk DA, Quinn DW (1996) An analysis of 1-D smoothed particle hydrodynamics kernels. J Comput Phys 126:165-180

32. Bonet J, Kulasegaram S (2000) Correction and stabilization of smooth particle hydrodynamics methods with applications in metal forming simulation. Int J Numer Methods Eng 47:1189-1214

33. Bonet J, Lok TSL (1999) Variational and momentum aspects of smooth particle hydrodynamics formulations. Comput Methods Appl Mech Eng 180:97-115

34. Gram A, Silfwerbrand J (2011) Numerical simulation of fresh SCC flow: applications. Mater Struct 44:805-813

35. Svec O, Skocek J, Stang H, Geiker MR, Roussel N (2012) Free surface flow of a suspension of rigid particles in a non-Newtonian fluid: a lattice Boltzmann approach. J Nonnewton Fluid Mech 179 180:32-42

36. Kulasegaram S, Karihaloo BL (2013) Fibre-reinforced, selfcompacting concrete flow modelled by SPH. Proc ICE Eng Comput Mech 166(EM1):22-31

37. Dransfield J (2003) Advanced concrete technology. In: Newman J, Choo BS (eds) Admixtures for concrete, mortar and grout, vol 2. Elsevier, Amsterdam 